\title{
CONDIÇÕES CLIMÁTICAS, CARACTERISTICAS DO FRUTO E SISTEMA DE COLHEITA NA QUALIDADE FISIOLÓGICA DE SEMENTES DE JACARANDÁ ${ }^{1}$
}

\author{
Cibele Chalita Martins², Líbia Belisario³, Camila de Aquino Tomaz e Claudemir Zucareli ${ }^{5}$
}

\begin{abstract}
RESUMO - As características dos frutos coletados e o sistema de colheita utilizado dependem da espécie que se está estudando. Esses parâmetros devem ser bem estabelecidos para permitir a obtenção de sementes com máxima germinação e vigor. Com o objetivo de determinar as características dos frutos e o sistema de colheita mais favorável à qualidade fisiológica de sementes de Jacaranda cuspidifolia Mart., por dois anos consecutivos foram colhidos frutos na árvore (verdes fechados, marrons fechados e marrons abertos) e frutos marrons no chão. As sementes foram extraídas, limpas e avaliadas quanto ao teor de água, germinação e vigor (primeira contagem do teste de germinação, comprimento da parte aérea e da radícula das plântulas e porcentagem de emergência). Para a obtenção de sementes de jacarandá com melhor qualidade fisiológica, os frutos devem ser colhidos na árvore marrons, abertos ou fechados e com teor de água inferior a 24,4\%.
\end{abstract}

Palavras-chave: Estágio de colheita, germinação, vigor e Jacaranda cuspidifolia.

\section{CLIMATIC CONDITIONS, FRUIT CHARACTERISTICS AND HARVEST SYSTEM ON PHYSIOLOGICAL QUALITY OF JACARANDA SEEDS}

\begin{abstract}
The characteristics of the collected fruits and its harvest system depend on the studied specie. These parameters must be well established to obtaining seeds with maximum germination and vigor. The objective of this study was to determinate the fruit characteristics and harvest system more favorable to physiological quality of Jacaranda cuspidifolia Mart. seeds, collecting during two years fruits from trees (green closed, brown closed and brown opened), and brown fruits on floor. Seeds were extracted, cleaned, and had evaluated the moisture content, germination and vigor (first counting of the germination test, seedling shoot and root growth and percentage of seedling emergence). Best physiological quality of jacarandá seeds was obtained with the harvest of brown fruits, opened or closed, on the trees with moisture content lower than $24.4 \%$.
\end{abstract}

Keywords:Harvest stage, germination, vigor and Jacaranda cuspidifolia.

\section{INTRODUÇÃO}

A maior consciência ecológica da população tem levado a sociedade e os governos à criação de leis de proteção ambiental e incentivos a projetos para a recuperação de áreas degradadas, reflorestamento de matas ciliares, implantação de parques públicos e privados e de reservas ecológicas. Isto tem feito aumentar a demanda por sementes de espécies florestais e a falta de sementes no mercado produtor de mudas arbóreas. Assim, faz-se necessário o desenvolvimento de tecnologias que permitam a obtenção de sementes florestais em quantidade e de qualidade para atender a esta realidade (BARBOSA et al., 2006).

\footnotetext{
${ }^{1}$ Recebido em 11.05.2007 e aceito para publicação em 19.05.2008.

${ }^{2}$ Departamento de Produção Vegetal da Universidade Estadual Paulista Júlio de Mesquita Filho(UNESP), . E-mail : <cibele@fca.unesp.br>

${ }^{3}$ Programa de Pós-Graduação em Agronomia da UNESP.

${ }^{4}$ Graduação em Agronomia da UNESP.

${ }^{5}$ Departamento de Agronomia da Universidade Estadual de Londrina (UEL), Londrina-PR.
} 
O conhecimento dos fatores que afetam a qualidade das sementes de espécies tropicais é importante tanto para a produção racional de sementes em áreas plantadas com esta finalidade quanto para o entendimento da reprodução das populações naturais. Kageyama (1984) destaca como dificuldades encontradas nesse tipo de pesquisa a quase impossibilidade de isolamento dos fatores ambientais envolvidos e aponta para a necessidade da realização destes estudos, principalmente devido à impossibilidade de extrapolação dos conceitos obtidos em regiões temperadas, especialmente de coníferas.

O jacarandá (Jacaranda cuspidifolia Mart.), conhecido como caroba, jacarandá e bolacheira, pertencente à família Bignoniaceae, é uma árvore de médio porte com altura de 3-10 m, utilizada na arborização e ornamentação de ruas, principalmente devido à beleza de suas flores arroxeadas. O florescimento ocorre nos meses de setembro a outubro e as sementes completam a maturação e dispersam aproximadamente um ano após, nos meses de agosto a setembro. A espécie produz anualmente grande quantidade de sementes viáveis, que não necessitam de tratamentos específicos para germinar, pois as sementes dessa espécie não apresentam dormência (LORENZI, 2000; SCALON et al., 2006). A germinação é epígea e ocorre de seis a 25 dias após a semeadura.

Sementes recém colhidas de $J$. cuspidifolia podem apresentar de 30 a 80\% de germinação (LORENZI 2000; CONTINI et al., 2003; SCALON et al., 2006), dependendo do lote de sementes. Entre os fatores que podem afetar a germinação destacam-se a maturidade das sementes e a dormência (CARVALHO \& NAKAGAWA, 2000).

Durante o processo de maturação, as sementes passam por modificações físicas, bioquímicas e fisiológicas até atingirem o ponto de maturidade fisiológica quando apresentam o máximo de germinação, vigor e matéria seca. Estas modificações são influenciadas por fatores ambientais e genéticos, havendo características marcantes e que sinalizam o ponto ideal de colheita de uma determinada espécie florestal (PIÑARODRIGUES \& AGUIAR, 1993; CARVALHO \& NAKAGAWA, 2000 ).

A colheita das sementes de espécies florestais no ponto de maturidade fisiológica é uma medida de aplicação prática, pois a colheita é manual. Em espécies colhidas mecanicamente, como as de grandes culturas agrícolas, isto não é possível, pois neste estágio as plantas da lavoura ainda estão verdes, o que não permite a entrada das máquinas, o corte e a trilha do material (CARVALHO \& NAKAGAWA, 2000). Ragagnin \& Dias (1987) identificaram que as sementes de $T$. chrysotricha (Bignoniaceae) devem ser colhidas com $58,9 \%$ de teor de água e $8 \mathrm{mg}$ de massa seca por semente para que se possa obter a máxima germinação $(96,6 \%)$.

No campo, para a colheita de sementes de espécies florestais são usualmente empregados aspectos físicos dos frutos, tais como cor, tamanho, cheiro e abertura espontânea, como referências para a identificação prática do estágio de colheita (SENA \& GARIGLIO, 1998). Para Jacaranda micrantha Cham. os frutos devem ser coletados quando mudam de cor, adquirindo coloração escura e em início de deiscência para a obtenção de sementes com máxima qualidade (CARVALHO, 1994). Para a maioria das espécies, a maturidade fisiológica é anterior à dispersão da semente (CARVALHO \& NAKAGAWA, 2000).

O objetivo deste trabalho é determinar as características dos frutos e o sistema de colheita mais favorável à qualidade fisiológica de sementes de $J$. cuspidifolia.

\section{MATERIAL E MÉTODOS}

Os frutos de jacarandá foram colhidos em 15 árvores matrizes situadas na Fazenda Experimental Lageado da Faculdade de Ciências Agronômicas da UNESP, campus de Botucatu (SP) em 30 de agosto de 2000 e 20 de agosto de 2001. As condições climáticas vigentes no local desde o florescimento das árvores, no mês de setembro de 1999 e 2000, até a colheita dos frutos estão apresentadas na Figura 1.

A colheita dos frutos foi realizada nos estágios de maturação e da forma descrita a seguir, constituindo quatro sistemas de colheita: frutos verdes colhidos na árvore; frutos marrons fechados colhidos na árvore; frutos marrons abertos colhidos na árvore e frutos marrons colhidos no chão. As sementes colhidas em cada um destes sistemas de colheita foram extraídas manualmente e imediatamente avaliadas quanto às seguintes características:

Teor de água - obtido por meio de quatro subamostras de 30 sementes a 1053 C por 24h (BRASIL, 1992) antes da instalação dos demais testes. 

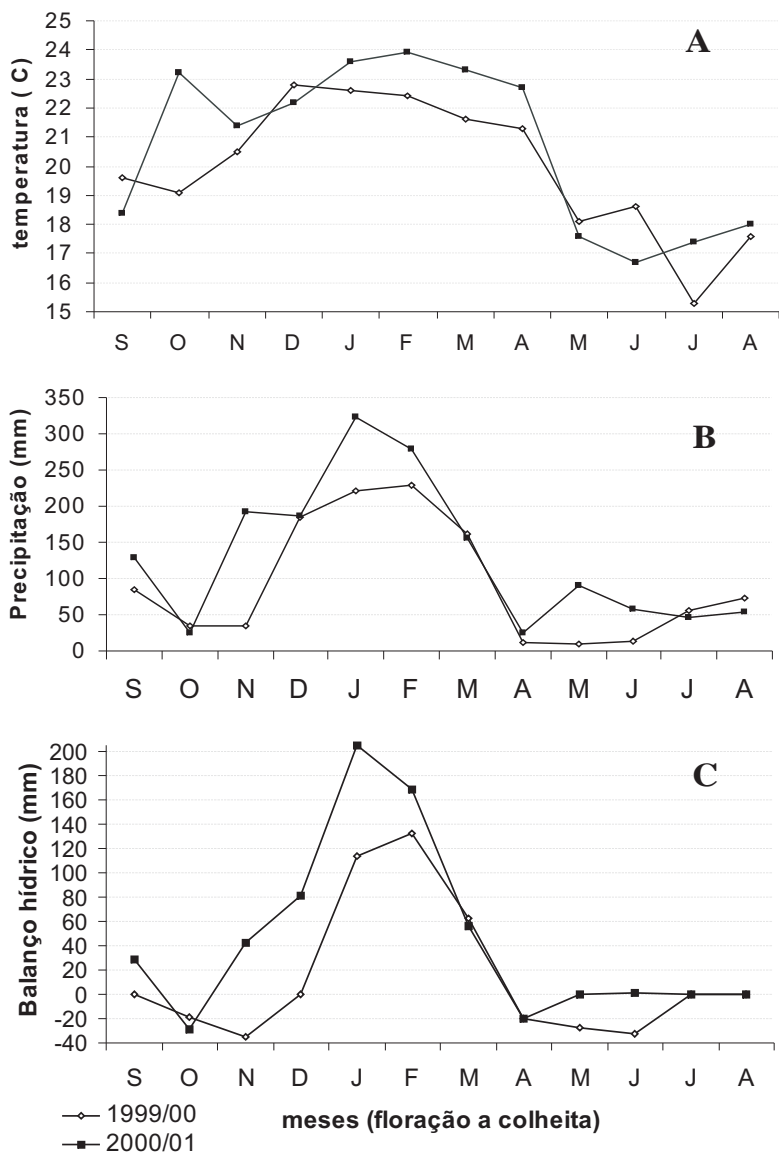

Figura 1 - Temperatura média (A), precipitação (B) e extrato do balanço hídrico (C) mensais vigentes durante a formação das sementes de jacarandá colhidas nos anos de 2000 e 2001.

Figure 1 -Average temperature (A), precipitation (B) and extract of monthly the hidrico rocking $(C)$ effective during the formation of the harvested seeds of jacarandá in the years of 2000 and 2001.

Teste de germinação - conduzido com quatro subamostras de 25 sementes em rolo de papel na temperatura de $25^{\circ} \mathrm{C}$ e luz (78 mol s- $1 \mathrm{~m}$-2/8h) e a contagem das plântulas foi realizada aos 17 dias após a semeadura (RAMOS \& BIANCHETTI, 1984), quando foram calculadas as porcentagens de plântulas normais, anormais, sementes dormentes e mortas(BRASIL, 1992).

Primeira contagem da germinação - realizada mediante a contagem das plântulas normais presentes no teste de germinação aos dez dias após a semeadura (VIEIRA \& CARVALHO, 1994).
Teste de emergência de plântulas - conduzido com quatro subamostras de 25 sementes semeadas em vermiculita umedecida com $50 \%$ da capacidade de retenção em água, dentro de caixas plásticas (20x30x6,5 $\mathrm{cm})$. O teste foi conduzido à temperatura constante de $25^{\circ} \mathrm{C}$ no escuro (VIEIRA \& CARVALHO, 1994), contabilizando-se as plântulas emersas aos 30 dias após a semeadura.

Comprimento de plântulas - as plântulas do teste de emergência foram retiradas das caixas após a contagem e lavadas em água corrente sobre peneira. O comprimento da parte aérea e da raiz primária da plântula foi mesurado com auxílio de uma régua (VIEIRA \& CARVALHO, 1994).

A análise estatística foi realizada em esquema fatorial $4 \times 2$ (quatro sistemas de colheita e dois anos de colheita) em delineamento inteiramente casualizado com quatro repetições e as médias foram comparadas pelo teste de Tukey $(\mathrm{P}>0,5)$.

\section{RESULTADOS E DISCUSSÃO}

O teor de água das sementes colhidas em 2000 e 2001 foi decrescente conforme progrediu a maturação que, no presente trabalho, acompanhou o sistema de colheita dos frutos (Quadro 1). Também foi observado que as sementes colhidas em 2000 apresentaram maior teor de água que as colhidas em 2001, devido à maior precipitação e menores temperaturas vigentes neste primeiro ano (1999/00) nos meses de julho e agosto, ou seja, no final da maturação dos frutos e próximo ao momento de colheita (Quadro 1 e Figura 1).

As temperaturas registradas durante a maior parte do período de formação das sementes colhidas em 2001 foram similares ou mais elevadas em 1 a $4{ }^{\circ} \mathrm{C}$ que as colhidas em 2000 . Somente em dois meses, setembro (florescimento) e junho (dois meses antes da colheita) o ano de 2000 superou a temperatura de 2001 em mais que $1^{\circ} \mathrm{C}$ (Figura 1$)$. A temperatura média registrada no período para as sementes colhidas em 2000 e 2001 foi de 20 e 21oC, respectivamente. Os processos metabólicos que ocorrem durante a maturação são afetados pela temperatura, e embora não tenham sido encontrados relatos para sementes de espécies florestais, para milho, soja e trigo são observadas reduções no desenvolvimento da semente em temperaturas inferiores a $22^{\circ} \mathrm{C}$ (MARCOS FILHO, 2005).

R. Árvore, Viçosa-MG, v.32, n.4, p.627-632, 2008 
Quadro 1 - Teor de água, primeira contagem, germinação e plântulas anormais em sementes de jacarandá provenientes de frutos colhidos em diferentes sistemas de colheita em dois anos consecutivos.

Table 1 - Moisture content. first counting of the germination test, germination and abnormal seedling of jacaranda seeds by collecting during two years with different harvest system.

\begin{tabular}{|c|c|c|c|c|c|c|c|c|c|c|}
\hline \multirow{3}{*}{$\begin{array}{c}\text { Parâmetros } \\
\text { Avaliados } \\
\text { Teor de água (\%) }\end{array}$} & \multirow{3}{*}{$\begin{array}{l}\text { Ano } \\
00\end{array}$} & \multicolumn{8}{|c|}{ Sistemas de colheita de frutos } & \multirow[t]{2}{*}{$\mathrm{CV} \%$} \\
\hline & & \multicolumn{2}{|c|}{ Verdes na árvore } & \multicolumn{2}{|c|}{$\begin{array}{l}\text { marrons fechados na } \\
\text { árvore }\end{array}$} & \multicolumn{2}{|c|}{$\begin{array}{l}\text { marrons abertos na } \\
\text { árvore }\end{array}$} & \multicolumn{2}{|c|}{ marrons no chão } & \\
\hline & & 44,1 & $\mathrm{aA}$ & 24,4 & $\mathrm{aB}$ & 11,3 & $\mathrm{aC}$ & 9,6 & $\mathrm{aD}$ & 3,81 \\
\hline & 01 & 33,2 & $\mathrm{bA}$ & 11,8 & $\mathrm{bB}$ & 9,1 & $\mathrm{bC}$ & 7,7 & $\mathrm{bD}$ & \\
\hline \multirow[t]{2}{*}{ Primeira Contagem (\%) } & 00 & 22 & $\mathrm{bC}$ & 26 & $\mathrm{bBC}$ & 31 & $\mathrm{bAB}$ & 32 & $\mathrm{aA}$ & 9,25 \\
\hline & 01 & 39 & $\mathrm{aAB}$ & 41 & $\mathrm{aA}$ & 38 & $\mathrm{aAB}$ & 34 & $\mathrm{aB}$ & \\
\hline \multirow[t]{2}{*}{ Germinação (\%) } & 00 & 50 & $\mathrm{bB}$ & 66 & $\mathrm{bA}$ & 69 & $\mathrm{bA}$ & 75 & $\mathrm{aA}$ & 7,48 \\
\hline & 01 & 79 & $\mathrm{aAB}$ & 84 & $\mathrm{aA}$ & 77 & $\mathrm{aAB}$ & 69 & $\mathrm{aB}$ & \\
\hline \multirow[t]{2}{*}{ Plântulas anormais (\%) } & 00 & 20 & $\mathrm{aA}$ & 20 & $\mathrm{aA}$ & 21 & $\mathrm{aA}$ & 12 & $\mathrm{aA}$ & 47,05 \\
\hline & 01 & 3 & bA & 4 & bA & 3 & bA & 4 & bA & \\
\hline \multirow[t]{2}{*}{ Sementes mortas (\%) } & 00 & 30 & $\mathrm{aA}$ & 14 & $\mathrm{aB}$ & 10 & $\mathrm{aB}$ & 13 & $\mathrm{aB}$ & 42,79 \\
\hline & 01 & 19 & $\mathrm{aA}$ & 13 & $\mathrm{aA}$ & 21 & $\mathrm{aA}$ & 27 & $\mathrm{bA}$ & \\
\hline \multirow[t]{2}{*}{ Emergência (\%) } & 00 & 34 & $\mathrm{bB}$ & 45 & $\mathrm{bB}$ & 63 & $\mathrm{bA}$ & 46 & $\mathrm{bB}$ & 13,60 \\
\hline & 01 & 76 & $\mathrm{aA}$ & 80 & $\mathrm{aA}$ & 81 & $\mathrm{aA}$ & 75 & $\mathrm{aA}$ & \\
\hline \multirow{2}{*}{$\begin{array}{l}\text { Comprimento de parte } \\
\text { aérea }(\mathrm{cm})\end{array}$} & 00 & 7,22 & $\mathrm{aA}$ & 8,15 & $\mathrm{aA}$ & 7,56 & $\mathrm{aA}$ & 7,80 & $\mathrm{aA}$ & 7,48 \\
\hline & 01 & 6,07 & bA & 6,48 & bA & 5,80 & bA & 5,80 & bA & \\
\hline \multirow{2}{*}{$\begin{array}{l}\text { Comprimento de raiz } \\
(\mathrm{cm})\end{array}$} & 00 & 4,48 & $\mathrm{bA}$ & 5,05 & $\mathrm{bA}$ & 4,77 & $\mathrm{bA}$ & 4,79 & $\mathrm{bA}$ & 7,04 \\
\hline & 01 & 7,85 & $\mathrm{aB}$ & 8,75 & $\mathrm{aA}$ & 8,38 & $\mathrm{aAB}$ & 7,83 & $\mathrm{aB}$ & \\
\hline
\end{tabular}

Médias seguidas por letras iguais, minúsculas na coluna e maiúsculas na linha, não diferem pelo teste de Tukey a 5\% de probabilidade.

Também quanto à precipitação, as sementes colhidas em 2001 foram formadas em condições mais favoráveis que as colhidas em 2000, registrando-se uma precipitação média no período de formação das sementes colhidas em 2000 e 2001 de, respectivamente, 93 e 130 mm, exceto no mês da colheita (agosto).

O balanço hídrico obtido durante o período de formação das sementes mostra que em 2001 houve maior ou igual excedente hídrico e menor déficit hídrico que em 2000. Em 2001 ocorreram dois meses de déficit, em outubro, após o florescimento e, em abril, numa fase de intermediária ao final do enchimento das sementes, enquanto em 2000 este período durou cinco meses. Além de mais duradouro, o déficit hídrico de 2000 foi mais intenso, chegando a aproximadamente $-40 \mathrm{~mm}$ no início do enchimento das sementes, em outubro e novembro, e de -20 a -40 mm em junho, julho e agosto, numa fase final e essencial de acúmulo de substâncias de reserva e formação das sementes (Figura 1).

Assim, as condições de temperatura e de balanço hídrico foram mais favoráveis à qualidade das sementes produzidas em 2001, que apresentaram maior porcentagem e velocidade na germinação, detectada pelo teste da primeira contagem, nos sistemas de colheita: frutos verdes da árvore, marrons fechados na árvore e abertos na árvore. Portanto, há uma indicação que as condições climáticas favoráveis vigentes durante a formação das sementes de 2001 anteciparam o ponto de maturidade fisiológica, possibilitando a obtenção de sementes com máxima capacidade germinativa e vigor mesmo no sistema de colheita em que os frutos estavam verdes e fechados (Quadro 1).

Somente no sistema de colheita marrons no chão, realizado após a dispersão, tanto as sementes colhidas em 2000 quanto as de 2001, apresentaram igual germinação e primeira contagem, indicando que o tempo adicional de permanência das sementes dentro dos frutos, mesmo que abertos, permitiu que as sementes de 2000 completassem a maturação. No entanto, a permanência dos frutos abertos no chão, comum em frutos de essências florestais, pode aumentar significativamente a porcentagem de sementes mortas, 
caso essas tenham atingido a maturidade fisiológica há mais tempo, como as de 2001, e as condições climáticas vigentes no mês da colheita sejam desfavoráveis à manutenção da qualidade das sementes, quanto à temperatura e precipitação (MARCOS FILHO, 2005). Adicionalmente, deve-se considerar que no chão, a água da chuva pode empoçar e existe maior quantidade de microorganismos que podem danificar as sementes.

Os resultados obtidos no teste da primeira contagem mostraram que a maturidade fisiológica das sementes de $J$. cuspidifolia depende do ano de produção, podendo ocorrer antes ou após a dispersão, como foi verificado em 2001 e 2000, respectivamente. Esses resultados confirmam relatos de que a identificação do ponto de maturidade fisiológica e de colheita de sementes de espécies florestais deve ser baseada na associação de diferentes índices de maturação e não somente no aspecto externo do fruto (BARBOSA, 1990).

A maior lentidão no amadurecimento devido às condições ambientais desfavoráveis vigentes durante a formação das sementes colhidas em 2000 fez com que a colheita de frutos verdes na árvore originasse sementes com maior porcentagem de mortas, menor porcentagem de germinação e de vigor detectado no teste da primeira contagem e na porcentagem de emergência.

A menor porcentagem de plântulas anormais e maior porcentagem de emergência e de comprimento de raiz confirmam a observação de que as condições de temperatura e de balanço hídrico vigentes durante a formação das sementes colhidas em 2001 resultaram em sementes de maior vigor e originaram plântulas de melhor qualidade, em todos os sistemas de colheita.

Somente quanto ao comprimento da parte aérea as sementes colhidas em 2001 apresentaram valores inferiores a 2000. Considerando-se que na germinação as reservas das sementes são utilizadas para o crescimento da raiz e da parte aérea e que a raiz é a primeira estrutura a ser emitida pela semente, podese supor que, no caso da plântula apresentar raízes comprometidas, as reservas são mais bem aproveitadas e assimiladas pela parte aérea. Martins \& Carvalho (1994) constataram que sementes de soja expostas as condições adversas de campo ou de secagem originaram plântulas com raízes lesadas, mas que não chegavam a ser plântulas anormais. Isto explicaria o maior desenvolvimento da parte aérea das sementes formadas em condições mais desfavoráveis, no ano de 2000.

\section{CONCLUSÕES}

O sistema de colheita indicado para a obtenção de sementes de jacarandá com máxima germinação e vigor, de forma independente das condições climáticas vigentes no ano de produção é o de frutos marrons na árvore, fechados ou abertos, e estas características podem ser utilizadas em conjunto com o teor de água da semente, que deve ser inferior a $24,4 \%$.

\section{REFERÊNCIAS}

BARBOSA, J.M. Maturação de sementes de Copaifera langsdorffii Desf. 1990. 144 f. Tese (Doutorado em Agronomia/Fitotecnia) Faculdade de Ciências Agrárias e Veterinárias, Universidade Estadual Paulista, Jaboticabal, 1990.

BARBOSA, L.M.; NEUENHAUS, E.; BARBOSA, K.; BARBOSA, J.M. Propostas para o desenvolvimento de políticas programas de produção de sementes e mudas de espécies florestais nativas. Informativo

ABRATES, Pelotas, 2006, v.16, n.1/2/3, p.66.

BRASIL. MINISTÉRIO DA AGRICULTURAE REFORMA AGRARIA. Regras para análise de sementes. Brasília: SNDA/DNDV/CLAV, 1992. 365p.

CARVALHO, N.M.; NAKAGAWA, J.

Sementes: ciência, tecnologia e produção. Jaboticabal: FUNESP, 2000. 588p.

CARVALHO, P.E.R. Espécies florestais brasileiras: recomendações silviculturais, potencialidades e uso da madeira. Brasília: EMBRAPA, CNPF 1994. 640 p.

CONTINI, A.Z.; Costa, R.B.; REGO, F.L.H.; SHEIDT, G.N. Caracterização morfológica da germinação e desenvolvimento inicial de Enterolobium timbouva Mart. (Leguminosae mimosoideae) e Jacaranda cuspidifolia Mart. (Bignoniaceae).. In: 54 CONGRESSO NACIONAL DE BOTÂNICA, 2003, Belém - Ananindeua - Pará. Desafios da Botânica Brasileira no Novo Milênio: Inventário, sistematização, Conservação e Diversidade Vegetal. Belém - Pará: MP - Design Gráfico, 2003.

R. Árvore, Viçosa-MG, v.32, n.4, p.627-632, 2008 
KAGEYAMA, P.Y. 1984. Fatores que afetam a produção de sementes florestais. In: SIMPÓSIO BRASILEIRO SOBRE TECNOLOGIA DE SEMENTES FLORESTAIS, 1. Anais... Belo Horizonte: IBDF. p.11-33.

LORENZI, H. Plantas daninhas no Brasil. $3^{\circ}$ edição. Nova Odessa, SP. Editora Plantarum. 2000.

MARCOS FILHO, J. Desenvolvimento (Maturação) de sementes. In: MARCOS FILHO, J. Fisiologia de sementes de plantas cultivadas. Piracicaba: FEALQ, p.91-142, 2005.

MARTINS, C.C., CARVALHO, N.M. Fontes de deterioração na produção de sementes de soja e respectivas anormalidades nas plântulas.

Revista Brasileira de Sementes, Brasília, v.16, n.2, p.168-82, 1994.

PIÑA-RODRIGUES, F.C.M.; AGUIAR, I.B. Maturação e dispersão de sementes. In: AGUIAR, I.B.; PIÑA-RODRIGUES, F.C.M.;

FIGLIOLIA, M.B. Sementes florestais tropicais. Brasília: ABRATES, p.215-274, 1993.
RAGAGNIN, L.I.M. \& DIAS L.L. Maturação fisiológica de sementes de Tabebuia chrysotricha. In: CONGRESSO BRASILEIRO DE SEMENTES, 5, 1987, Gramado. Resumos...p. 128.

RAMOS, A.; BIANCHETTI, A. Influência da temperatura e do substrato na germinação de sementes florestais. In. SIMPÓSIO

INTERNACIONAL: Métodos de produção e controle de qualidade de sementes e mudas florestais. Anais... Curitiba. 1984. p. 252-274.

SCALON, S.P.Q., MUSSURY, R.M., SCALON FILHO, H., FRANCELINO, C.S.F., FLORÊNCIO, D.K.A. Armazenamento e tratamento prégerminativos em sementes de jacarandá (Jacaranda cuspidifolia Mart.). Revista Árvore. 2006, v.30, n.2, p.179-185.

SENA, C.M.; GARIGLIO, M.A. Sementes florestais: colheita, beneficiamento e armazenamento. Brasília: IBAMA, 1998. 26 p.

VIEIRA, R.D.; CARVALHO, N.M. Testes de vigor em sementes. Jaboticabal: FUNEP, 1994. 164p. 